\title{
Çoklu bağ yaralanmalarında ön çapraz bağa yaklaşım
}

\section{Treatment of the anterior cruciate ligament in multi-ligament injuries}

\author{
N. Reha Tandoğan ${ }^{1}$, H. Uğur Gönç ${ }^{2}$, Metin Polat ${ }^{2}$, Altuğ Tanrı̈̈ver ${ }^{2}$ \\ ${ }^{1}$ Ortoklinik, Ankara \\ ${ }^{2}$ Çankaya Ortopedi, Ankara
}

Ön çapraz bağ (ÖÇB) yaralanmaları en sık iç yan bağ (IYYB) yaralanmaları ile birlikte görülür. IYB'nin yüksek iyileşme yeteneği nedeniyle bu yaralanmaların güncel tedavisi dizlik ile iYB'nin konservatif tedavisi sonrası gecikmiş ÖÇB rekonstrüksiyonudur. ÖÇB cerrahisi sırasında rezidüel medial laksite saptanırsa, aynı seansta medial yapılar da rekonstrükte edilebilir. Çoklu diz bağ yaralanmaları/diz çıkığında da ÖÇB sıklıkla yaralanır. Bu durumda güncel tedavi yaralanmadan sonraki ilk üç hafta içinde hasarlı bütün yapıların onarılmasıdır. Eklem sertliğinden kaçınmak için iki aşamalı cerrahi de uygulanabilir, ancak ekstremiteye yük vermeden önce bütün rekonstrüksiyonlar tamamlanmış olmalıdır. Tibial eminensiya kopma kırıkları için internal tespit uygundur. ÖÇB gövdesinden yaralanmalarda oto veya allogreftler ile rekonstrüksiyon yapılmalıdır. Çoklu bağ cerrahisinde greftlerin etkin kullanımı ve cerrahi süre açısından tek demet ÖÇB rekonstrüksiyonu tercih edilir. Erken dönemde diz hareketine başlayacak şekilde güçlü greftler ve sağlam tespit yöntemleri kullanılmalı, cerrahinin sonunda dizin tam hareket açıklığında diz stabil olmalıdır. Çoklu bağ cerrahisinin sonuçları izole ÖÇB kadar iyi değildir, tedavinin hedefi günlük yaşamda ağrısız ve stabil bir diz elde etmek olmalıdır. Spora dönüş mümkün olabilir ancak yaralanma öncesi seviyelerde olması nadirdir.

Anahtar sözcükler: ön çapraz bağ; iç yan bağ; diz çoklu bağ yaralanması; bağ rekonstrüksiyonu
The most frequent combined knee ligament injury involves the anterior cruciate ligament $(A C L)$ and medial collateral ligament (MCL). Conservative treatment of $M C L$ in a brace followed by delayed $A C L$ reconstruction is the preferred treatment due to the intrinsic healing capacity of the MCL. Residual medial laxity at the time of ACL surgery can be addressed by medial collateral ligament reconstruction. ACL injuries can also be a component of knee dislocations/multiligament injuries. Repair of all injured structures in the first three weeks after injury is advisable. Staged surgery may also be employed to prevent stiffness; however, all reconstructions should have been completed before the patients start weight bearing. Tibial eminence avulsions can be managed with internal fixation. Auto or allograft reconstruction should be performed for mid-substance injuries of the ACL. Single bundle anatomical cruciate ligament reconstructions should be preferred to decrease surgical time and cost-effective use of allografts. Strong graft materials and stable fixation methods should be employed to be able start early knee motion and rehabilitation. The knee should be stable at all flexion angles at the end of ligament reconstruction. The outcomes of ACL surgery in multi-ligament injuries are inferior to those of isolated ACL reconstructions. The goal of surgery should be to achieve a stable and painless knee in activities of daily living. Return to sports is possible but rarely matches the pre-injury level.

Key words: anterior cruciate ligament; medial collateral ligament; knee multi-ligament injury; ligament reconstruction

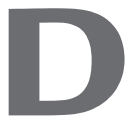
iğer bağ yaralanmaları ile birlikte görülen ön çapraz bağ (ÖÇB) en sık kombine ÖÇB ve iç yan bağ yaralanması olarak karşımıza çıkar (Şekil 1). Bunun yanında, düşük ve yüksek enerjili bütün diz çıkıklarında ÖÇB yaralanması görülebilir, bu yaralanma bağın gövdesinden olabileceği gibi tibial eminensiya kopma kırığı olarak da karşımıza çıkabilir. Tedavisi ve prognozu tamamen farklı olan bu iki yaralanma şekli bu yazıda ayrı ayrı incelenecektir.

\section{ÖN ÇAPRAZ BAĞ VE IÇ YAN BAĞ KOMBINE YARALANMALARI}

Spor yaralanmaları sırasında ÖÇB ile birlikte en sık yaralanan bağ iç yan bağdır (IYB). Evre III IYB yaralanmalarının \%78'inde eşlik eden bağ yaralanmaları görülür ve bunların \%95'i ÖÇB'yi ilgilendirir. ${ }^{[1]}$ Futbol, Amerikan futbolu ve kayak gibi yüksek enerjili yaralanma riski olan sporlarda kombine yaralanmalar daha sıktır. Dize uygulanan valgus ve rotasyonel kuvvetler ile önce IYB, zorlanma devam ederse de ÖÇB yırtığı ortaya çıkar.

- İletişim adresi: Prof. Dr. N. Reha Tandoğan, Ortoklinik, Cinnah Cad. 51/4 Çankaya, 06680, Ankara

Tel: 0312 - 4390206 e-posta: rtandogan@ortoklinik.com

- Geliș tarihi: 24 Mart $2020 \quad$ Kabul tarihi: 2 Nisan 2020 

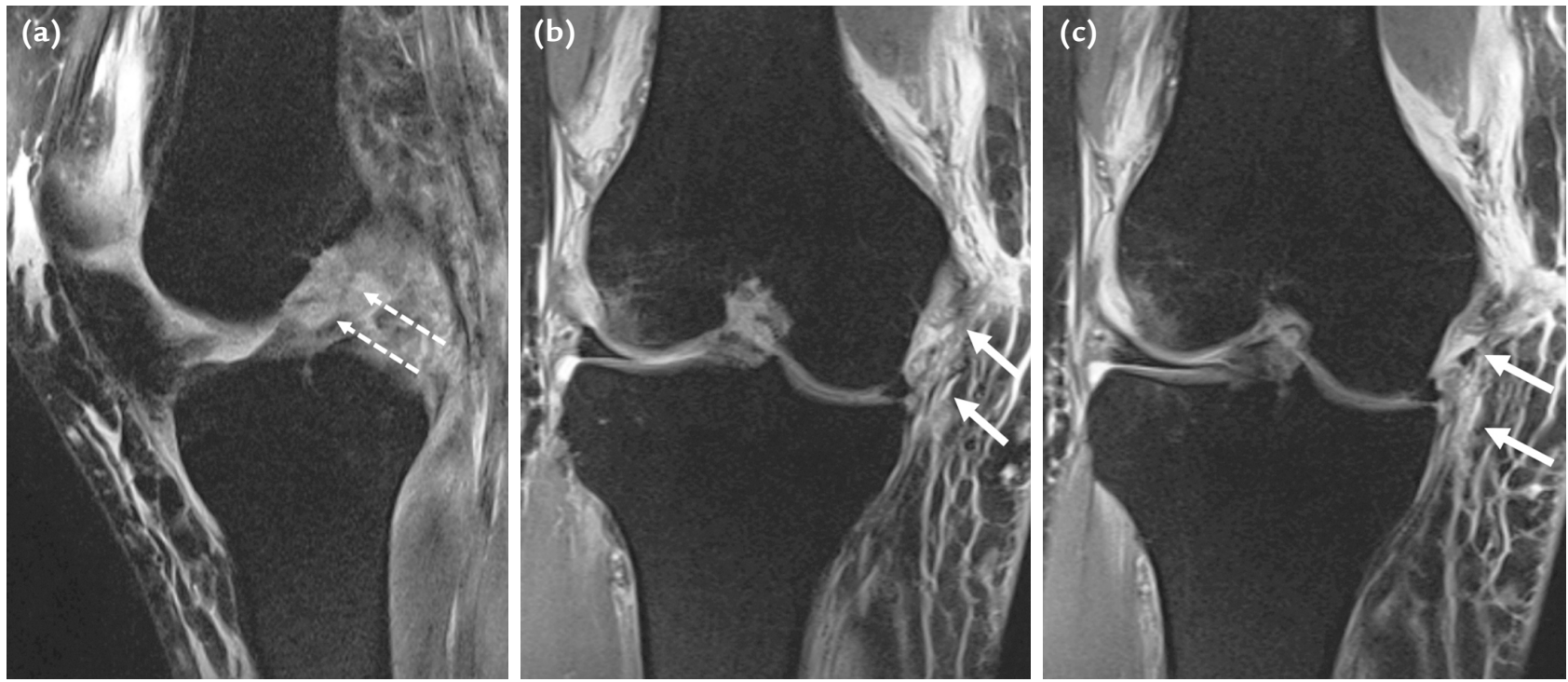

Şekil 1. a-c. Kombine ön çapraz bağ ve iç yan bağ yaralanmasının T2 yağ baskılamalı manyetik rezonans görüntüleri. Kesikli ok (a) ön çapraz bağ kopması, düz oklar (b) iç yan bağın gövdesinden olan yaygın yaralanmayı göstermekte. Lateral femoral kondildeki kemik iliği ödemi medial yaralanmanın bir başka işareti (c).

Evre I ve II iYB yaralanmalarının eşlik ettiği ÖÇB yaralanmaları, izole ÖÇB yırtıkları gibi tedavi edilebilir. Bu hastalarda IYB için ayrıca bir cerrahi uygulamaya gerek yoktur, herhangi bir dizlik kullanımı da gerekmez. Medialde sebat eden ağrı bazı hastalarda rehabilitasyonu geciktirebilir ve diz hareketlerinin kazanılması daha zor olabilir. Kronik dönemde de düşük dereceli iYB laksitesinin sonuçları etkilemediği gösterilmiştir. Hara ve ark., kronik Evre II medial laksitesi olan olgularda, izole ÖÇB rekonstrüksiyonunun sonuçlarının başarılı olduğunu ve rezidüel medial laksitenin önemli olmadığını öne sürerler. ${ }^{[2]}$

Kombine ÖÇB ve Evre III IYB yaralanmalarında üç farklı tedavi seçeneği vardır.

\section{Hem iYB Hem de ÖÇB için Erken Cerrahi}

1980'lerde popüler olan bu tedavide, hem iYB hem de ÖÇB aynı seansta cerrahi olarak onarılır. İkinci bir kesi gerektiren bu cerrahi sonrasında, artrofibrozis riski ve rehabilitasyon sorunları daha yüksektir. Grant ve ark., akut ÖÇB rekonstrüksiyonu ve IYB primer onarım yapılan dört çalışmanın meta-analizinde, 129 olguda yüksek stabilite oranları ve Lysholm skorları saptamışlardır. $\left.{ }^{1}\right]$ Ancak hastaların \%38'inde artrofibrozis nedeniyle ek girişimler gerekli olmuş ve uzun süreli izlemde bile \%10'dan fazla kuadriseps güç kaybı saptanmıştır. IYB için konservatif tedavi uygulanan olgular ile sonuçlar arasında önemli farklar olmaması nedeniyle bu erken kombine cerrahi günümüzde yaygın kabul görmemektedir.

Akut dönemde her iki bağın da cerrahi tedavi edilmesini gerektiren bazı durumlar da vardır. Bunlar anteromedial rotator instabilitesi olan hastalardır. ${ }^{[3]}$ Burada ÖÇB ve iYB'ye ek olarak bütün medial kapsüler yapıların yaralanması vardır, "dial” testi bariz olarak pozitiftir. Bu olgularda ilk üç hafta içinde bütün yapıların cerrahi olarak onarılması gerekir.

Erken kombine cerrahi gerektiren bir başka durum, iYB'nin tibial taraftan koparak eklem içine aspire olması ve medial menisküs altına sıkışmasıdır (Şekil 2). iYB'nin tibial yapışma yerinden ayrılarak pes anserinus tendonlarının üzerine çıkmasına dizin Stener lezyonu adı verilir ve bu durumda da erken dönemde kombine iYB ve ÖÇB onarımı gereklidir. ${ }^{[4]}$

\section{Sadece ÖÇB Onarımı, iYB Konservatif Tedavi}

Kombine yaralanmalarda başka bir yaklaşım, akut dönemde ÖÇB rekonstrüksiyonu yapılması ve IYB iyileşmesi için dizlik uygulamasıdır. Bu görüşü savunanlar, erken dönemde ÖÇB rekonstrüksiyonu yapılmasının, iYB iyileşmesi için uygun bir biyomekanik ortam hazırladığını ve dizde hareket kısıtlılığına yol açmadığını öne sürerler. Halinen ve ark., 47 kombine yaralanması olan olguda, izole ÖÇB rekonstrüksiyonu yapılan hastalar ile kombine ÖÇB ve IYB rekonstrüksiyonu yapılan olguların stabilite sonuçları arasında bir fark 

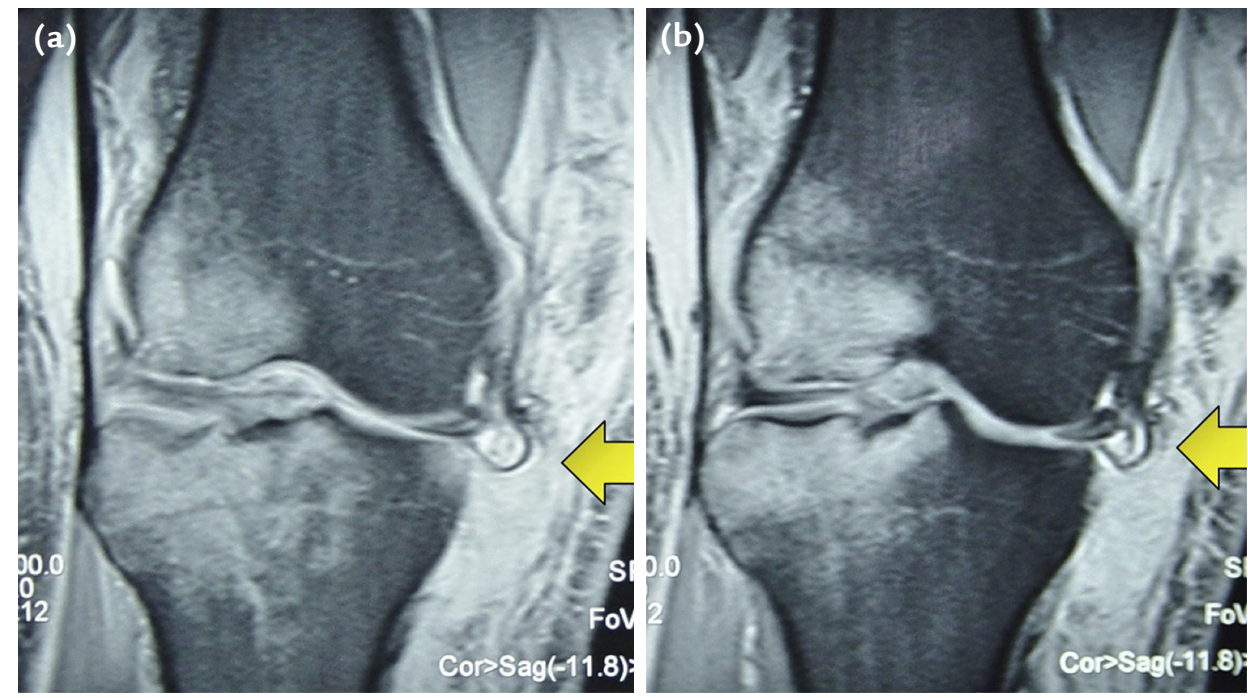

Şekil 2. a, b. İç yan bağın tibial yapışma yerinden kopup eklem içine aspirasyonunun koronal manyetik rezonans görüntüleri (a, b). (Tandoğan NR. Dizin medial tarafyaralanmaları. Iç̧inde: Tandoğan NR, editör. Diz Bă̆ Yaralanmaları. Ankara: TOTBiD Spor Travmatolojisi Şubesi Yayınları, Bayt Yayıncılık; 2013. ss.107-116.'dan izin alınarak basılmıştır.)

olmadığını göstermişlerdir. ${ }^{[5]}$ Yazarlar, akut olgularda izole ÖÇB onarımının, IYB iyileşmesi için yeterli olduğunu öne sürmektedirler. Benzer şekilde Millett ve ark. da, erken izole ÖÇB rekonstrüksiyonunun, konservatif izlenen IYB iyileşmesini olumlu etkileyeceğini 19 olguda bildirmişlerdir. ${ }^{[6]}$ Bu tekniğin en önemli sorunu, altı haftalık dizlik tedavisi ile yeterli iYB iyileşmesi sağlanamazsa, medial stabilitenin sağlanması için ikinci bir cerrahiye ihtiyaç olmasıdır.

\section{iYB Konservatif Tedavi, ÖÇB Gecikmiş Rekonstrüksiyon}

Kombine ÖÇB ve IYYB yaralanmalarında günümüzde en yaygın uygulanan tedavi şekli iYB için konservatif izlem, ÖÇB için gecikmiş rekonstrüksiyondur. Akut dönemde IYB'nin iyileşmesi için altı hafta eklemli dizlik ile konservatif tedavi uygulanır. Bu sürede dizlik içinde tam diz hareket açıklığının kazanılması için çalışılmalıdır. Uzun bacak alçısı ile immobilizasyon uygun değildir. Özellikle femoral yapışma noktasından olan IYB kopmalarında tam ekstansiyonu kazanmak zor olabilir, bunun için uygun egzersizler ve fizik tedavi yöntemlerine başvurulabilir. Altıncı hafta sonunda ÖÇB rekonstrüksiyonu yapılır, bu sırada medial laksite tekrar değerlendirir, 5 mm'den daha fazla bir medial laksite varsa IYB rekonstrüksiyonu da işleme eklenir. iYB için dizlik ile konservatif tedavi sonrası gecikmiş ÖÇB onarımı yapılan altı çalışmanın meta-analizinde Grant ve ark., çalışmaların beş tanesinde medial stabilitenin tam olarak sağlandığını ve yüksek IKDC (International Knee Documentation Committee) skorlarına ulaşıldığını bulmuşlardır. ${ }^{[1]}$ Buna karşın bir çalışmada hastaların \%21'inde 3-5 mm rezidüel medial laksite saptanmıştır. Femoral yapışma noktasına yakın iYB yaralanmalarının daha az laksite ile iyileştiği bulunmuştur.

Gecikmiş ÖÇB rekonstrüksiyonu yapılırken, rezidüel medial laksite çok iyi değerlendirilmeli, gerektiğinde zorlamalı grafiler ile medial laksite derecesi objektif olarak doğrulanmalıdır. Medial laksitesi fazla olan olgularda IYB rekonstrüksiyonu yapılmaz ise, ÖÇB greftine binen yükler ve başarısızlık riskinin artacağı unutulmamalıdır. ${ }^{[7]}$ Konservatif tedavi edilen IYB sonrası izole ÖÇB rekonstrüksiyonu yapılacak hastalarda greft tipinin önemi yoktur. Svantesson ve ark., 622 olguluk serilerinde, patellar tendon, tek veya çift hamstring greftlerinin kullanımı arasında revizyon riski açısından bir fark bulamamışlardır. ${ }^{[8]}$ Buna karşın, hem ÖÇB hem de IYB rekonstrüksiyonu yapılacak ise greft seçimi önemlidir. Çap ve uzunluğun uygun olması açısından ÖÇB için patellar tendon veya kemik bloklu kuadriseps tendon greftleri kullanılabilir, hamstring tendonları IYB onarımı için tercih edilir. Karşı dizden greft alımı gündeme gelebilir. İsveç/Danimarka kayıt sistemindeki 19.457 hastanın değerlendirildiği bir çalışmada, konservatif tedavi edilen IYB yaralanması sonrası ÖÇB onarımı yapılan hastalardaki revizyon riskinin, izole ÖÇB onarımlarına göre daha yüksek olduğu bulunmuştur. ${ }^{[9]}$ Bu yükssek başarısızlık nedeninin, tam olarak 

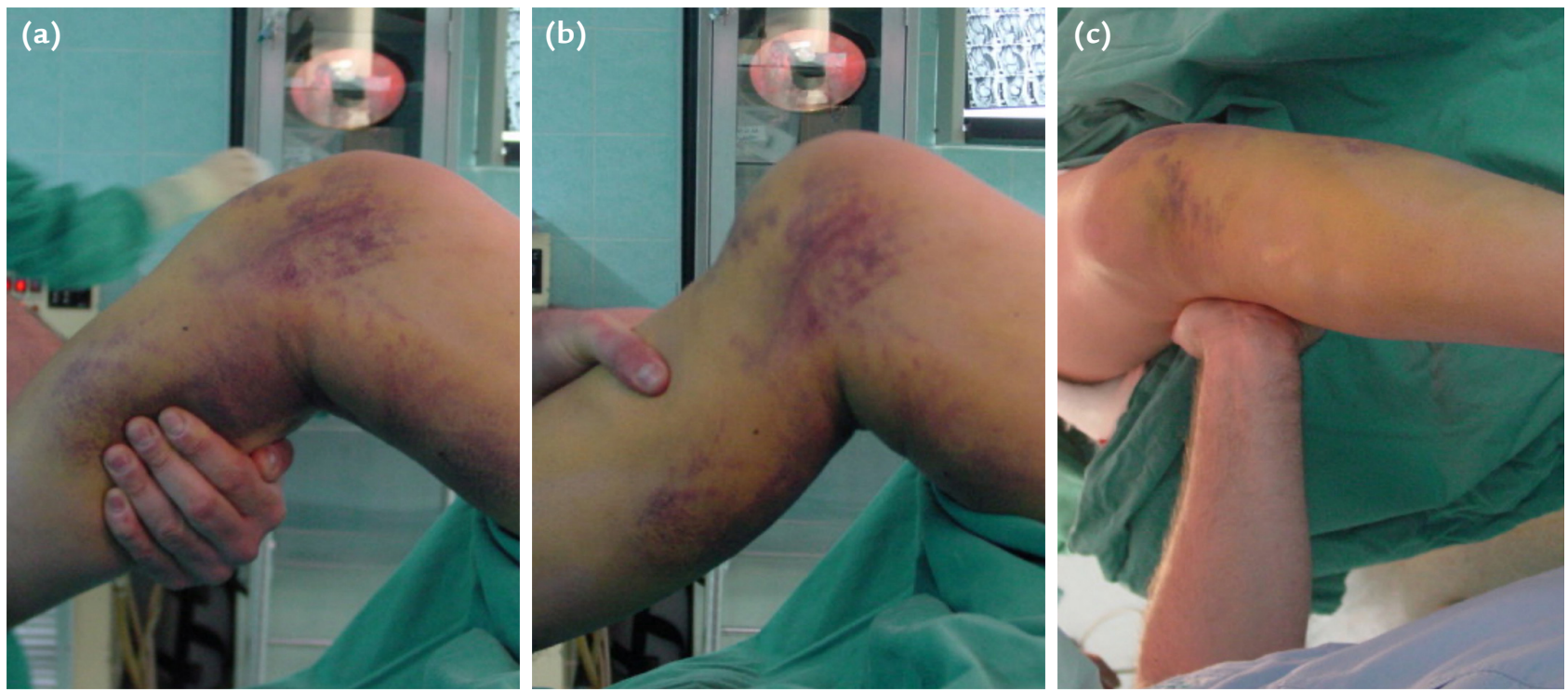

Şekil 3. a-c. Kombine ön-arka çapraz bağ ve iç yan bağ yaralanması ve patellar tendon rüptürü olan hastanın muayenesi. Ön çekmece (a), arka çekmece (b) ve valgus zorlama (c) testlerinde ileri derecede laksite mevcut, medialde son nokta yok.

iyileşmeyen iYB'nin yol açtığı laksitenin ÖÇB greftine binen yükleri artırması olduğu düşünülmektedir.

\section{Kronik Dönemde Kombine ÖÇB ve IYB Rekonstrüksiyonu}

Tedavi edilmemiş veya konservatif tedavi sonrası semptomatik rezidüel medial laksitesi olan hastalarda, kombine ÖÇB ve IYB rekonstrüksiyonu yapılabilir. Özellikle güreş gibi dizin valgusa zorlandığı sporlarda birkaç milimetrelik bir medial gevşeklik bile sporcula$r$ engelleyebilir. Kronik dönemde kombine IYB + ÖÇB rekonstrüksiyonu yapılacak ise yukarıda belirtilen greft seçimi önemlidir. Cerrahi sırasında IYB ve ÖÇB tünellerinin birbirleri ile çakışması beklenmez. Allogreft kullanılmayacaksa, greft kaynaklarının verimli kullanılması açısından tek demet anatomik ÖÇB rekonstrüksiyonu tercih edilmelidir. Medial laksite sadece fleksiyonda belirgin, ekstansiyonda kayboluyorsa izole yüzeyel iYB rekonstrüksiyonu yapılabilir. Eğer medial laksite hem fleksiyon hem de ekstansiyonda belirgin ise hem yüzeyel iYB hem de posterior oblik bağ (postero-medial kapsül) onarılmalıdır. Bunun için Lind tekniğ[i[10] (tek femoral tünel, iki tibial tünel, tek tendon grefti) veya LaPrade'nin ${ }^{[11]}$ anatomik medial rekonstrüksiyon tekniği (iki femoral, iki tibial tünel, iki tendon grefti) tercih edilebilir. Kombine ÖÇB ve IYB rekonstrüksiyonu ile \%80'in üzerinde olguda normal veya normale yakın IKDC skorları bildirilmiştir. Rezidüel medial laksite 0,8-2,9 mm arasındadır, ancak olguların \%7-10'unda $5^{\circ}$ 'den fazla diz hareket kaybı bildirilmiştir. ${ }^{[12,13]}$

\section{ÇOKLU BAĞ YARALANMALARINDA ÖÇB Yaralanma Özellikleri}

ÖÇB ve IYB'nin birlikte yaralanmaları hariç, dizin ikiden fazla bağının yırtılmış olması diz çıkığı olarak kabul edilir. Diz çıkıkları nadirdir, insidansı 100 hasta/yılı için 0,072 olarak bildirilmiştir. \%13-17'si açık yaralanma şeklindedir. ${ }^{[14]}$ Çoklu bağ yaralanmaları en sık yüksek enerjili yaralanmalar sonrası ortaya çıkarlar. Motosiklet kazaları, endüstriyel kazalar ve doğal afetler en sık görülen nedenlerdir. Yüksek enerjili yaralanmalar sonrası oluşan çoklu bağ yaralanmalarında popliteal arter yaralanması insidansı \%30'lara kadar çıkar; sinir hasarı, cilt yaralanmaları ve osteokondral kırıklar daha fazla görülür. Daha nadir olarak düşük enerjili spor yaralanmaları sırasında da çoklu bağ yaralanması olabilir, bunlarda popliteal arter yaralanması insidansı \%4 civarındadır; sinir yaralanması, cilt sorunları ve osteokondral kırıkların görülme riski daha azdır. Son yıllarda morbid obez hastalarda tanımlanan ultra-düşük enerjili yaralanmalar, tedavisi en zor çıkıklardır. ${ }^{[15]}$ Bu çıkıklar genellikle merdivenden takılma ve burkulma sonrası olurlar ancak damar yaralanması riski çok yüksektir, tedavi sırasında komplikasyon görülme riski fazladır.

Diz çıkığına, birçok yumuşak doku ve kemik yaralanmaları eşlik edebilir. ${ }^{[16]}$ Bunlar içinde en sık görüleni peroneal sinir yaralanmasıdır (\%16-50), ancak karşı kompartmanda ezilme kırıkları ve kıkırdak yaralanmaları, tibial rim kırıkları, patellar tendon kopmaları ve patella çıkıkları da görülebilir (Şekil 3). Her tür menisküs yaralanması çoklu bağ yaralanmalarına eşlik 

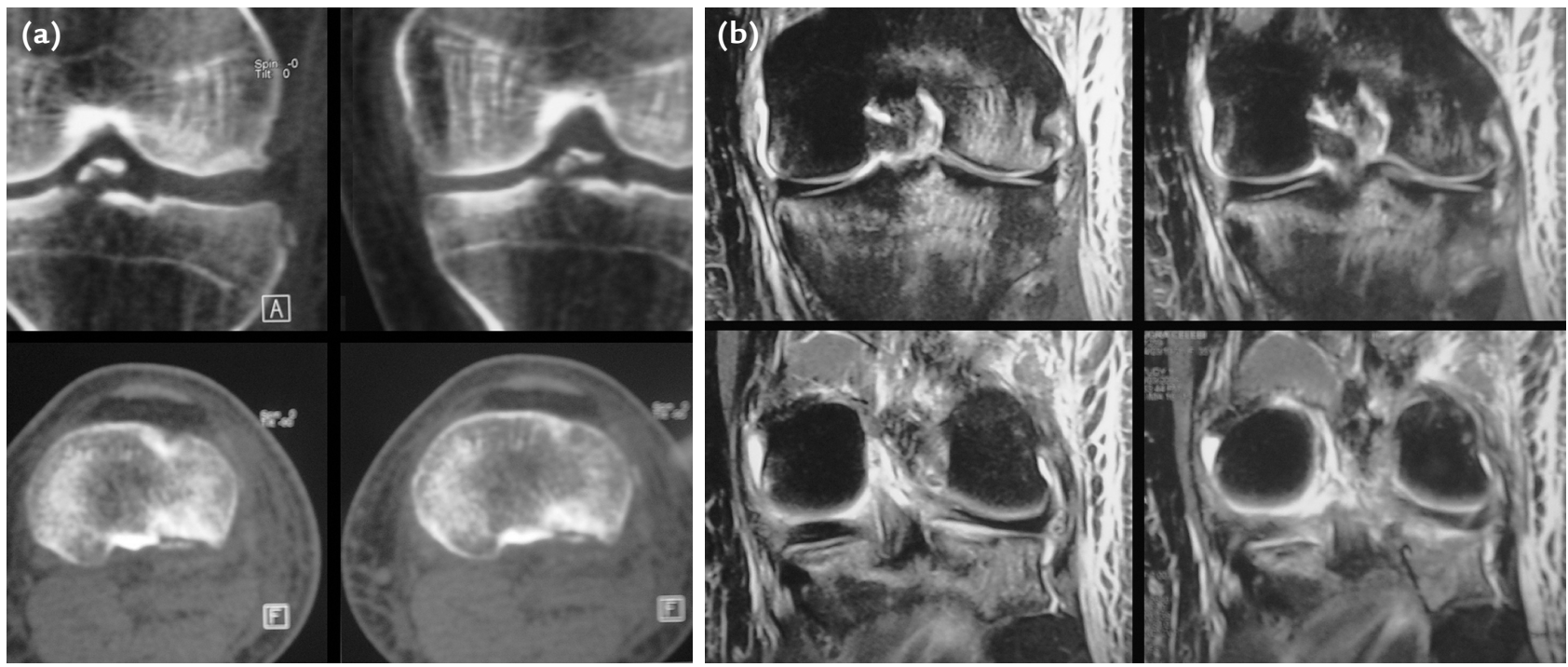

Şekil 4. a, b. Tibia eminensiya kopma kırı̆̆ı, posterolateral tibia platosunda ezilme kırığı ve iç yan bağ yaralanması olan hastanın görüntüleri: Koronal ve aksiyel bilgisayarlı tomografi kesitlerinde tibial eminensiya ve posterolateral plato kırığı (a); koronal manyetik rezonans kesitlerinde iç yan bağın femoral insersiyondan ayrılması ve lateral kompartmanda yaygın travmatik kemik iliği ödemi (b).

edebilir. En sık menisko-tibial veya menisko-femoral bağın kemikten ayrılması görülür. Bu yırtıklar tamir için çok uygundurlar. Kök yırtıklarının da çoklu bağ yaralanmalarında beklenenden daha sık görüldüğü (yaklaşık \%10 olguda) bildirilmiştir. ${ }^{[17]}$

\section{Cerrahi Zamanlama}

Çoklu bağ yaralanmalarında erken cerrahi sadece açık çıkıklarda, damar yaralanması varsa, yan bağlar eklem içine aspire olmuşsa, patellar tendon rüptürü varsa ve dizin redüksiyonunu korumak için eksternal fiksatör gerekli ise yapılabilir. Bunun dışındaki durumlarda cerrahi tedavi, dizdeki akut şişlik ve ağrı azalıp sinovyal sızdırmazlık sağlandıktan sonra yapılır. Cerrahi tedavi için en uygun süre yaralanmadan sonraki ilk 2-3 haftadır. Yaralanmadan altı hafta geçtikten sonra oluşan fibrozis ve skar dokusu nedeniyle dokuları tanımak ve ayrı ayrı onarmak mümkün olmaz. Bu durumda akut tamir şansı kaybolur ve rekonstrüktif cerrahiler gündeme gelir. Damar yaralanması nedeniyle fasyotomi yapılmışsa, bunlar kapatılmadan bağ rekonstrüksiyonlarının yapılması uygun değildir ve kronik dönemde cerrahi yapılır. Eklemi ilgilendiren büyük kırıklar var ise (örn.; Hoffa kırığı, tibia plato kırı̆̆ı) önce kırık tespiti yapılır, bağ rekonstrüksiyonu kronik döneme bırakılmalıdır.

\section{Cerrahi Prensipler}

Çoklu bağ yaralanmalarına girişim mükemmel bir anatomi bilgisi, cerrahi sırasında birden fazla çözüm üretebilecek deneyim, özenli bir ameliyat öncesi planlama, yeterli otolog ve allogreft kaynağı, uygun implantların ve enstrümantasyonun varlığını gerektirir. Akut dönemde yapılan cerrahilerdeki onarımların sonuçları kronik dönemde yapılan rekonstrüksiyonlardan üstündür. Hasta tam yük vermeye başlamadan önce yaralanmış olan bütün yapılar onarılmış olmalıdır. Kısmi cerrahiler ve yaralanmanın sadece bazı komponentlerinin düzeltilmesi başarısızlığa mahkumdur; greft ve kaynak israfindan başka bir sonuç doğurmaz. ${ }^{18]}$

Çoklu bağ yaralanmalarında iki ana yöntem izlenebilir. En sık uygulanan yöntem, bütün yaralanmış yapıların aynı seansta onarılmasıdır. Bu seçenekte artrofibrozis oluşmasını önlemek için erken harekete başlayacak şekilde sağlam greft ve tespit materyallerinin kullanımı şarttır. Cerrahinin sonunda dizin tam hareket açıklığında stabilite sağlanmış olmalıdır. ${ }^{[19]}$ Daha az uygulanan ikinci yöntem ise arka çapraz (AÇB) ve periferik yapıların ilk seansta onarımı, altı hafta sonra ÖÇB'nin rekonstrüksiyonudur. Artrofibrozis riskinin daha az olduğu düşünülen bu strateji genellikle daha az deneyimli ekipler tarafından tercih edilir, iki cerrahi işlemi ve sonrasında uzamış rehabilitasyon ve spora dönüşü içerir. ${ }^{[20,21]}$

\section{Tibial Eminensiya Kopma Kırıkları}

Çoklu bağ yaralanmalarında ÖÇB'nin tibial eminensiya kopma kırıkları, bağın gövdesinden olan yırtıklarına göre daha nadir görülür (Şekil 4). Altmış üç olguluk bir diz çıkığı serisinde tamir edilebilir ÖÇB avülziyon kırı̆gı oranı \%19 olarak bildirilmiştir. ${ }^{[22]}$ 

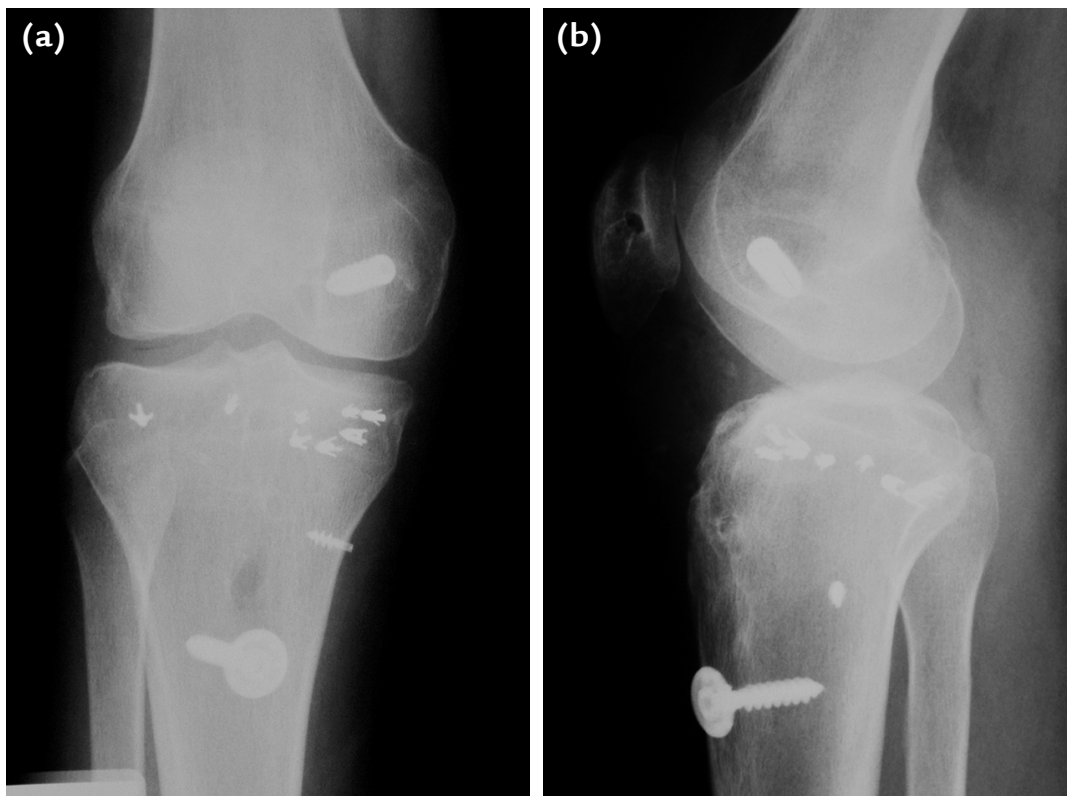

Şekil 5. a, b. Şekil 3'teki hastanın cerrahi tedaviden üç yıl sonraki radyolojik görüntüleri. Allogeft ile ön çapraz bağ ve arka çapraz bağ rekonstrüksiyonu, medial yapılara çoklu dikiş çıpaları ile primer tamir (a); patellar tendona primer tamir ve hamstring tendonu ile güçlendirme yapılmış (b).

ÖÇB'nin liflerinde belirgin hasar ve plastik deformasyon yoksa, eminensiya kırığının tespiti yeterli bir tedavi sağlar. Kopan parça büyükse kanüle vidalar, parçalı ise güçlendirilmiş sütür materyalleri ile trans-osseöz onarım uygundur. Onarım için kullanılacak tünellerin veya vidaların, diğer bağ tünelleri ile (örn.; $A C ̧ B$ veya iYB) çakışmaması için özen gösterilmelidir. Tespit erken harekete başlayabilecek kadar sağlam olmalı ve karşı femur kıkırdağına zarar verebilecek yüksek profilli implantlardan kaçınılmalıdır. Kaynama sağlandıktan sonra kanüle vidaların çıkartılması gerekir, buna karşın güçlendirilmiş sütür materyalleri hem vida kadar sağlam tespit sağlar hem de çıkartılmaları gerekmez.

\section{Bağın Gövdesinden Yaralanmalar}

Çoklu bağ yaralanmasına eşlik eden ÖÇB ve bağın gövdesini ilgilendiren yırtıklarda primer tamirin yeri yoktur ve bağın rekonstrükte edilmesi gerekir. Gerek cerrahi süreyi uzatmamak, gerekse de greft kaynaklarının etkin kullanımı açısından tek demet anatomik rekonstrüksiyonlar tercih edilmelidir. Zaten yaralanmış olan dizdeki morbiditeyi artırmamak ve sağlam dinamik stabilize edici yapılara zarar vermemek için çoklu bağların rekonstrüksiyonunda allogreftlerin kullanımı tercih edilir. ${ }^{[23]}$ Allogreftlerin sayı ve boyut kısıtlamaması olmaması en önemli avantajlarıdır. Buna karşın, otogreftlere göre daha geç inkorpore olurlar, düşük de olsa hastalık taşınması riskleri vardır, pahalıdırlar ve sonuçları otogreftlere göre biraz daha kötüdür. ${ }^{[24]}$ Allogreft kullanımı mümkün değilse, karşı dizden tendon greftleri elde edilebilir.

Birden fazla greft kullanılacaksa en sağlam olanı AÇB için ayrılmalıdır. AÇB rekonstrükte edilip diz uygun pozisyona getirildikten sonra dizin geri kalanı bu onarımın üzerine inşa edilmelidir. ÖÇB ve $A C ̧ B$ birlikte rekonstrükte edilecekse tünel çakışmasından kaçınmak için tibial giriş noktaları arasında en az $3 \mathrm{~cm}$ mesafe bırakılmalı ve AÇB tüneli daha distal ve orta hatta yakın açılmalıdır. Buna karşın ÖÇB tibial tüneli daha proksimal ve medialde yer alır. Kombine ön-arka çapraz bağ yaralanmalarında dizin anatomik pozisyonunu değerlendirmek ve bağ greftlerinin gerginliğini ayarlamak kolay olmayabilir. Bu durumda önce AÇB grefti $70^{\circ}$ fleksiyonda gerdirilmeli ve normal tibial "step-off" sağlandıktan sonra tespit edilmelidir. Daha sonra ÖÇB grefti $0-30^{\circ}$ fleksiyon arasında tespit edilmelidir. Periferik yapıların tamirinde dikiş çapaları tercih edilmeli, büyük vida-pul implantlarından kaçınılmalıdır (Şekil 5). Cerrahi işlem tamamlandıktan sonra, dizin tam hareket açıklığı ve stabilitesi kontrol edilmelidir. Cerrahi sonunda stabil olmayan veya hareket kısıtlılığı olan dizin rehabilitasyon aşamasında düzelmesi mümkün değildir. 


\section{Rehabilitasyon}

Çoklu bağ yaralanmalarının rehabilitasyonu izole ÖÇB yaralanmalarından farklıdır. Yumuşak doku iyileşmesi için 1-2 hafta süreyle dizlik ile immobilizasyon uygun olur. Sonrasında eklemli dizlikler içinde hareket başlanabilir. Özellikle AÇB'ye yük bindirmeyen prone pozisyonda fleksiyon egzersizlerine erken dönemde başlanmalıdır. Çoklu bağ yaralanmalarının rehabilitasyonunda en önemli sorun, yerçekimi ile AÇB greftinin gevşemesi endişesidir. Son yıllarda bütün fleksiyon açılarında tibiaya öne doğru kuvvet uygulayabilen dinamik dizliklerin geliştirilmesi ile bu sorun büyük ölçüde giderilmiştir. Bu dizlikler ile erken dönemde güvenli bir şekilde hareket başlanabilir. Zira artrofibrozis bu cerrahilerin en sık görülen komplikasyonudur. Çoklu bağ yaralanması cerrahisi sonrası 6-8 hafta süreyle koltuk değneği ile kısmi yük verilmelidir. Spora dönüş, eğer olacaksa bir yıldan önce değildir.

\section{Klinik Sonuçlar}

Yaralanma şekillerinin çok farklı olması nedeniyle sonuçlar hakkında bir genelleme yapmak mümkün değildir, ancak bazı çıkarımlardan bahsedilebilir. Çoklu bağ yaralanmalarının cerrahi tedavi sonuçları, izole yaralanmalardan daha kötüdür. Daha uzun ve zorlu bir rehabilitasyon gerektirir. Spora dönüş her zaman mümkün değildir, cerrahi tedavinin temel amacı hastanın günlük yaşamında ağrısız ve stabil bir diz elde etmek olmalıdır. Çoklu bağ yaralanmalarının cerrahi tedavisi ile ilgili 21 çalışmanın meta-analizinde, Everhart ve ark., spora dönüş oranını $\% 60$ olarak bulmuşlardır. ${ }^{[25]}$ Ancak bu nadiren yaralanma önceki düzeye ulaşabilir. İşe dönüş mümkündür ama daha düşük seviyededir. Kötü sonuçlar obezite, konservatif tedavi, yüksek enerjili yaralanma ve damar yaralanması ile ilişkili bulunmuştur.

Akut dönemde (ilk 3-4 hafta içinde) yapılan cerrahilerin sonuçları, geç dönemde yapılan rekonstrüksiyonlardan daha iyidir. Yakın zamanda yapılan sekiz çalışmanın meta-analizinde erken cerrahi müdahalenin sonuçları geç rekonstrüksiyondan belirgin olarak üstün bulunmuştur. ${ }^{[26]}$

Damar onarımı yapılan hastaların sonuçları, damar yaralanması geçirmeyen hastalara göre daha kötüdür. Bunda yaralanmaya yol açan enerjinin fazla olması, kas iskemisi, fasyotomi gerekliliği ve gecikmiş cerrahi yapma zorunluluğunun etkisi olabilir. ${ }^{[27]}$

Menisküslerin korunmuş olması başarılı bir sonuç ve artrozun engellenmesi açısından önemlidir. Eşlik eden kıkırdak hasarının şiddetli olması ve kırıklı çıkıklar sonucu olumsuz etkiler.
Postero-lateral köşe yaralanmalarında rekonstrüksiyon primer tamirden üstündür. Medial taraf yaralanmalarında primer tamir ve rekonstrüksiyon sonuçları benzerdir, bu nedenle doku kalitesi iyiyse medial tarafta primer onarım denenebilir.

Politravmanın eşlik ettiği diz çıkıklarının sonuçlarının, dizin stabilitesi sağlansa bile izole diz çıkıklarına göre daha kötü fonksiyonel sonuçlara ulaştığı gösterilmiştir. ${ }^{[28]}$

\section{KAYNAKLAR}

1. Grant JA, Tannenbaum E, Miller BS, Bedi A. Treatment of combined complete tears of the anterior cruciate and medial collateral ligaments. Arthroscopy 2012;28(1):110-22. Crossref

2. Hara K, Niga S, Ikeda H, Cho S, Muneta T. Isolated anterior cruciate ligament reconstruction in patients with chronic anterior cruciate ligament insufficiency combined with grade II valgus laxity. Am J Sports Med 2008;36(2):333-9. Crossref

3. Engebretsen L, Lind M. Anteromedial rotatory laxity. Knee Surg Sports Traumatol Arthrosc 2015;23(10):2797-804. Crossref

4. Tandogan NR, Kayaalp A. Surgical treatment of medial knee ligament injuries: Current indications and techniques. EFORT Open Rev 2016;1(2):27-33. Crossref

5. Halinen J, Lindahl J, Hirvensalo E, Santavirta S. Operative and nonoperative treatments of medial collateral ligament rupture with early anterior cruciate ligament reconstruction: a prospective randomized study. Am J Sports Med 2006;34(7):1134-40. Crossref

6. Millett PJ, Pennock AT, Sterett WI, Steadman JR. Early ACL reconstruction in combined $A C L-M C L$ injuries. J Knee Surg 2004;17(2):94-8. Crossref

7. Battaglia MJ 2nd, Lenhoff MW, Ehteshami JR, Lyman S, Provencher MT, Wickiewicz TL, Warren RF. Medial collateral ligament injuries and subsequent load on the anterior cruciate ligament: a biomechanical evaluation in a cadaveric model. Am J Sports Med 2009;37(2):305-11. Crossref

8. Svantesson E, Hamrin Senorski E, Östergaard M, Grassi A, Krupic F, Westin O, Samuelsson K. Graft Choice for Anterior Cruciate Ligament Reconstruction With a Concomitant Nonsurgically Treated Medial Collateral Ligament Injury Does Not Influence the Risk of Revision. Arthroscopy 2020;36(1):199211. Crossref

9. Svantesson E, Hamrin Senorski E, Alentorn-Geli E, Westin O, Sundemo D, Grassi A, Custovic S, Samuelsson K. Increased risk of ACL revision with non-surgical treatment of a concomitant medial collateral ligament injury: a study on 19, 457 patients from the Swedish National Knee Ligament Registry. Knee Surg Sports Traumatol Arthrosc 2019;27(8):2450-9. Crossref

10. Kim S-J, Lee D-H, Kim T-E, Choi N-H. Concomitant reconstruction of the medial collateral and posterior oblique ligaments for medial instability of the knee. J Bone Joint Surg $\mathrm{Br}$ 2008;90-B(10):1323-7. Crossref

11. LaPrade RF, Wijdicks CA. Surgical technique: development of an anatomic medial knee reconstruction. Clin Orthop Relat Res 2012;470(3):806-14. Crossref

12. Dong JT, Chen BC, Men XQ, Wang F, Hao JD, Zhao JN, Wang XF, Zhang XY, Sun R. Application of triangular vector to functionally reconstruct the medial collateral ligament with double-bundle allograft technique. Arthroscopy 2012;28(10):1445-53. Crossref 
13. Zhang $H$, Sun $Y$, Han $X$, Wang $Y$, Wang L, Alquhali $A$, Bai $X$. Simultaneous Reconstruction of the Anterior Cruciate Ligament and Medial Collateral Ligament in Patients With Chronic ACL-MCL Lesions: A Minimum 2-Year Follow-up Study. Am J Sports Med 2014;42(7):1675-81. Crossref

14. Chowdhry M, Burchette D, Whelan D, Nathens A, Marks $P$, Wasserstein D. Knee dislocation and associated injuries: an analysis of the American College of Surgeons National Trauma Data Bank. Knee Surg Sports Traumatol Arthrosc 2020;28(2):568-75. Crossref

15. Carr JB, Werner BC, Miller MD, Gwathmey FW. Knee Dislocation in the Morbidly Obese Patient. J Knee Surg 2016;29(4):278-86. Crossref

16. Medina O, Arom GA, Yeranosian MG, Petrigliano FA, McAllister DR. Vascular and nerve injury after knee dislocation: a systematic review. Clin Orthop Relat Res 2014;472(9):2621-9. Crossref

17. Kosy JD, Matteliano L, Rastogi A, Pearce D, Whelan DB. Meniscal root tears occur frequently in multi-ligament knee injury and can be predicted by associated MRI injury patterns. Knee Surg Sports Traumatol Arthrosc 2018;26(12):3731-7. Crossref

18. Tandoğan NR, Kayaalp A, Yazıcı A. Diz çıkı̆̆ı. İçinde: Taşer ÖF, Bayraktar B, editörler. Futbol Hekimliği. İstanbul: Nobel Tıp Kitabevi; 2020. ss.449-56.

19. Tandoğan NR. Çoklu Bağ Yaralanmalarında Ön Çapraz Bağ. İçinde: Tandoğan NR, Kayaalp A, editörler. Ön Çapraz Bağ Cerrahisinde Güncel Kavramlar. Ankara: Sincan Matbaası; 2014. ss.129-42.

20. Subbiah M, Pandey V, Rao SK, Rao S. Staged arthroscopic reconstructive surgery for multiple ligament injuries of the knee. J Orthop Surg (Hong Kong) 2011;19(3):297-302. Crossref
21. Stannard JP, Bauer KL. Current concepts in knee dislocations: PCL, ACL, and medial sided injuries. J Knee Surg 2012;25(4):287-94. Crossref

22. Twaddle BC, Bidwell TA, Chapman JR. Knee dislocations: where are the lesions? A prospective evaluation of surgical findings in 63 cases. J Orthop Trauma 2003;17(3):198-202. Crossref

23. Billières J, Labruyère $C$, Steltzlen $C$, Gonzalez $A$, Boisrenoult $P$, Beaufils P, Pujol N. Multiligament knee injuries treated by one-stage reconstruction using allograft: Postoperative laxity assessment using stress radiography and clinical outcomes. Orthop Traumatol Surg Res 2019. Crossref

24. Tisherman R, Wilson K, Horvath A, Byrne K, De Groot J, Musahl V. Allograft for knee ligament surgery: an American perspective. Knee Surg Sports Traumatol Arthrosc 2019;27(6):1882-90. Crossref

25. Everhart JS, Du A, Chalasani R, Kirven JC, Magnussen RA, Flanigan DC. Return to Work or Sport After Multiligament Knee Injury: A Systematic Review of 21 Studies and 524 Patients. Arthroscopy 2018;34(5):1708-16. Crossref

26. Hohmann E, Glatt V, Tetsworth K. Early or delayed reconstruction in multi-ligament knee injuries: A systematic review and meta-analysis. Knee 2017;24(5):909-16. Crossref

27. Sanders TL, Johnson NR, Levy NM, Cole PA Jr, Krych AJ, Stuart M, Levy BA. Effect of Vascular Injury on Functional Outcome in Knees with Multi-Ligament Injury: A MatchedCohort Analysis. J Bone Joint Surg Am 2017;99A(18):156571. Crossref

28. Woodmass JM, Johnson NR, Mohan R, Krych AJ, Levy BA, Stuart MJ. Poly-traumatic multi-ligament knee injuries: is the knee the limiting factor? Knee Surg Sports Traumatol Arthrosc 2018;26(9):2865-71. Crossref 